Article

\title{
Divinyl Sulfone Cross-Linked Cyclodextrin-Based Polymeric Materials: Synthesis and Applications as Sorbents and Encapsulating Agents
}

\section{Julia Morales-Sanfrutos ${ }^{1}$, Francisco Javier Lopez-Jaramillo ${ }^{1, *}$, Mahmoud A. A. Elremaily ${ }^{1,2}$, Fernando Hernández-Mateo ${ }^{1}$ and Francisco Santoyo-Gonzalez ${ }^{1, *}$}

1 Departamento de Química Orgánica, Facultad de Ciencias, Instituto de Biotecnología, Universidad de Granada, E1871 Granada, Spain; E-Mails: juliams@ugr.es (J.M.-S.); fhmateo@ugr.es (F.H.-M.)

2 Department of Chemistry, Faculty of Science, Sohag University, Sohag 82524, Egypt; E-Mail: msremaily@yahoo.com

* Authors to whom correspondence should be addressed; E-Mails: fjljara@ugr.es (F.J.L.-J.); fsantoyo@ugr.es (F.S.-G.); Tel.: +34-958-248-087 (F.S.-G.); +34-958.243187 (F.J.L.-J.); Fax: +34-958-243-320 (F.S.-G. \& F.J.L.-J.)

Academic Editor: Eduardo Sobarzo-Sánchez

Received: 18 November 2014 / Accepted: 13 February 2015 / Published: 19 February 2015

\begin{abstract}
The aim of this study was to evaluate the crosslinking abilities of divinyl sulfone (DVS) for the preparation of novel water-insoluble cyclodextrin-based polymers (CDPs) capable of forming inclusion complexes with different guest molecules. Reaction of DVS with native $\alpha$-cyclodextrin $(\alpha-C D), \beta$-cyclodextrin $(\beta-C D)$ and/or starch generates a variety of homo- and hetero-CDPs with different degrees of crosslinking as a function of the reactants' stoichiometric ratio. The novel materials were characterized by powder X-ray diffraction, electron microscopy and for their sorption of phenol and 4-nitrophenol. They were further evaluated as sorbents with phenolic pollutants (bisphenol A and $\beta$-naphthol) and bioactive compounds (the hormone progesterone and curcumin). Data obtained from the inclusion experiments show that the degree of cross-linking has a minor influence on the yield of inclusion complex formation and highlight the important role of the CDs, supporting a sorption process based on the formation of inclusion complexes. In general, the inclusion processes are better described by a Freundlich isotherm although an important number of them can also be fitted to the Langmuir isotherm with $\mathrm{R}^{2} \geq 0.9$, suggesting a sorption onto a monolayer of homogeneous sites.
\end{abstract}


Keywords: cyclodextrins; divinyl sulfone; sorbents, encapsulating agents; phenols; curcumin

\section{Introduction}

Chemical cross-linked cyclodextrin polymers (CDPs) [1] are a novel class of polysaccharide-based materials that have been conceived to utilize the remarkable intrinsic capacity of cyclodextrins (CDs) to form inclusion complexes (ICs) to form advanced networks that synergistically exhibit high sorption properties and particular guest selectivity. Advantages accruing from these capabilities are relevant for the applicability of such materials in diverse fields ranging from remediation technologies [2,3] to drug delivery $[4,5]$, among others.

The removal of organic contaminants from aquatic systems is a crucial issue and recent developments concerning the use of CDPs for environmental purposes have determined their implementation as valuable sorbents [6,7]. In contrast to other materials routinely used in environmental remediation, CDPs are designed to make organic contaminants insoluble and for the enrichment and removal of organic pollutants and heavy metals from soil, atmosphere and water. Overall, the adsorption technique is the best method for the removal of toxic substances from water and is a much better than other physical techniques (flocculation, froth flotation, etc.) because of its efficacy and economy [8]. The ability of adsorption to remove toxic chemicals without disturbing the quality of water or leaving behind any toxic degraded products has augmented its usage in comparison to electrochemical, biochemical or photochemical degradation processes. A wide variety of solids ranging from synthetic materials to others of natural origin such as polysaccharides have been employed as sorbents in this technique. CDs have recently been the object of numerous modifications and polymerization studies in the search for non-conventional but cheaper and more effective sorbents. The easy enzymatic preparation of CDs from starch and the presence of a central hydrophobic cavity in their structures, making them ideal hosts in the formation of ICs of aromatics and other hydrophobic organic pollutants, are advantageous characteristics. Nonetheless, because of their water solubility native CDs must be unavoidably processed into water-insoluble solid forms (CDPs) in order to be implemented as usable sorption materials.

On the other hand, CDPs are opening new perspectives in pharmacotherapy where they are emerging as advanced delivery systems [4,5,9-11]. In a broad sense, native and chemically derivatized CDs have emerged as an important tool in the formulator's armamentarium as ideal assistants to overcome the most relevant challenges of the formulation of both old drugs and novel biopharmaceuticals, namely the balance between solubility, stability and permeability $[9,12]$. Encapsulation of a guest drug inside the $\mathrm{CD}$ by the formation of ICs provides an efficient hydrophilic camouflage that produces remarkable physicochemical consequences. For example, an improvement in the apparent solubility and dissolution rate in the case of poorly water-soluble drug candidates [13]. Interestingly, CDs can cooperatively work when they are close together, provoking a displacement in the complex formation equilibrium towards the ICs [14]. For this reason, CDs have been used as outstanding building blocks for the development of novel supramolecular drug delivery systems such 
as poly(pseudo)rotaxanes [11], polymer-CD grafted and polymer-guest grafted physical networks [15] and also chemically cross-linked CDPs [1].

The most direct and general method for the synthesis of cross-linked CDPs is by reacting the hydroxyl groups of native CDs with bi- or multi-functional molecules (cross-linker agents) to form stable cross-linked networks. Epoxides, isocyanates, active carbonyl compounds, polycarboxylic acids and some of their activated derivatives (chlorides and anhydrides) as well as aldehydes are among the cross-linkers reported for the preparation of CDPs. The most thoroughly studied CD polymerization is the cross-linking reaction with the epoxide epichlorohydrin (EPI) [16] although ethylene glycol diglycidyl ether (EGDE) has emerged as a non-toxic and environmentally friendly alternative to the diepoxide counterpart. Diisocyanates - toluene diisocyanate (TDI) and hexamethylene diisocyanate (HDI) - are similarly useful reagents to obtain CDPs, but they usually require organic solvents as reaction media $[17,18]$ On the other hand, active carbonyl compounds, such as N,N-carbonyldiimidazole (CDI) and diphenylcarbonate (DPC), have been utilised as cross-linkers to generate CDPs. Finally, polycarboxylic acids and some of their halides and anhydride derivatives have been reported as "eco-friendly" cross-linkers (particularly in the case of citric acid) being applied with success in the preparation of water-insoluble CDPs [19-21].

It should be mentioned that the already well-established capabilities of divinyl sulfone (DVS) to act as a non-zero length cross-linker have never been exploited for the preparation of CDPs. Vinyl sulfones readily undergo conjugate additions as excellent Michael acceptors because of the electron poor nature of their double bond [22,23]. A significant body of work has been devoted to the conjugate additions of vinyl sulfones with carbon nucleophiles, but other heteroatomic nucleophiles involving nitrogen, sulfur and oxygen can also participate efficiently in these reactions in a protic environment where the use of a base catalysis is necessary, except in the case of amines. Among the different bisvinyl sulfones, DVS is the most popular cross-linker reagent because of its reactivity, stability, solubility in water and affordable price, having found a plethora of applications in bioconjugation [24], proteomics [25] and also in the preparation of polysaccharide-based networks. In this latter case, the properties of the electrophilic double bond of DVS have attracted research into the crosslinking of diverse natural polysaccharides (cellulose, dextran, agarose and hyaluronic acid). Efforts have been directed mainly for the preparation of hydrogel-based materials with improved mechanical and chemical properties to be used as advanced materials in a variety of applications: chromatographic supports, controlled drug-delivery systems and biocompatible biomaterials for biomedical applications.

In the present work the potential of DVS as a cross-linker is exploited for the preparation of novel water-insoluble homo- and hetero-CDPs by cross-linking native $\alpha-\mathrm{CD}, \beta-\mathrm{CD}$ and starch [26]. The capabilities of the novel materials as sorbents for the removal of a variety of some representative phenolic pollutants and as encapsulating agents for bioactive compounds such as a model steroid hormone (progesterone) and a naturally phenolic compound (curcumin) are also explored and reported. 


\section{Results and Discussion}

\subsection{Preparation and Characterization of DVS Cross-Linked Polymers}

With the aim of preparing novel CD-based sorbents, $\alpha$ - and $\beta$-CD were chosen as starting materials for accessing CDPs polymers synthesized using DVS as cross-linking reagent as shown in Scheme 1 [26]. It is well established that the electron-deficient double bond of the vinyl sulfone groups in DVS is reactive toward the $\mathrm{OH}$ groups present in natural linear polysaccharides (cellulose, dextran, agarose and hyaluronic acid), a reaction that usually occurs under alkaline conditions. Considering that the $\mathrm{pK}_{\mathrm{a}}$ of the $\mathrm{OH}$ groups of the Glc units in $\mathrm{CD}$ is about 12-13, carbonate buffer ( $\mathrm{pH}$ 12.0) was chosen to perform their deprotonation to yield alkoxide ions. The primary $\mathrm{OH}$ groups at the $\mathrm{C}-6$ position exhibit a higher reactivity with respect to the secondary $\mathrm{OH}$ groups. Being active nucleophiles, the alkoxide groups form covalent linkages with the electrophilic double bonds of DVS. Different DVS:Glc stoichiometries and reaction times were tested to ensure the reaction of all the vinyl sulfone groups. ${ }^{1} \mathrm{H}-\mathrm{NMR}$ analysis revealed that, regardless of the DVS:Glc stoichiometry, the vinyl signal vanished after $7-8 \mathrm{~h}$ of reaction at room temperature.

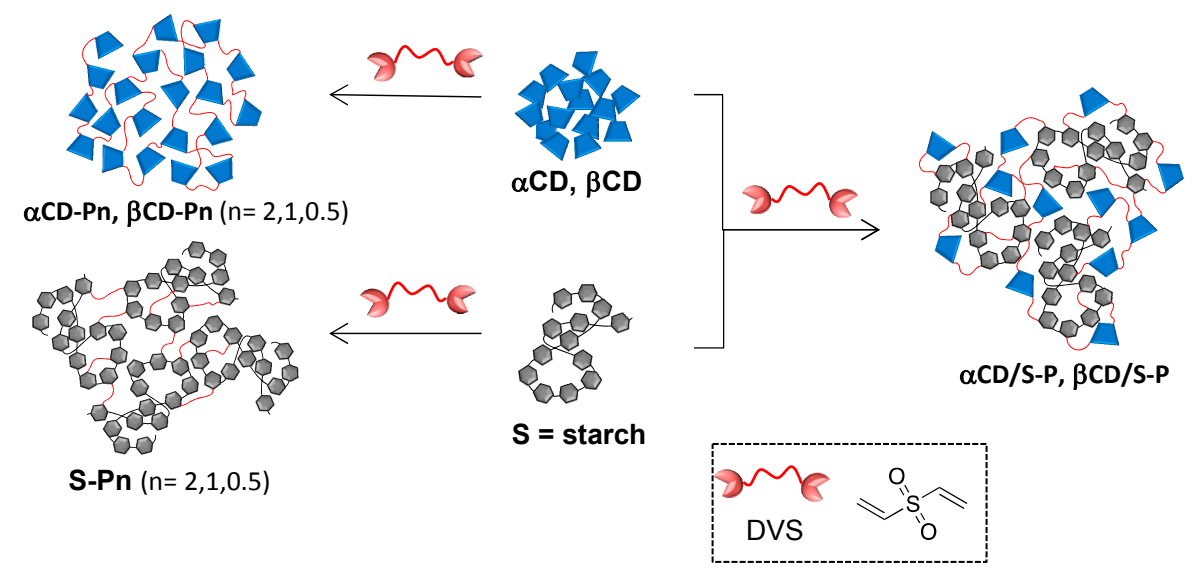

Scheme 1. Synthesis of DVS cross-linked homo- ( $\boldsymbol{\alpha C D}-\mathbf{P n}, \boldsymbol{\beta C D}-\mathbf{P n}, \mathbf{S - P n})$ and hetero-polymers $(\boldsymbol{\alpha C D} / \mathbf{S}-\mathbf{P}$ and $\boldsymbol{\beta C D S}-\mathbf{P}) ; n=$ stoichiometry DVS:Glc ratio: $n=2(2: 1)$, $n=1(1: 1), n=0.5(0.5: 1)$.

CDs are well known for their capability to form inclusion complexes and their cross-linking yields polymers that exhibit high sorption properties and particular guest selectivity. In order to have a reference material without such capability, starch was cross-linked with DVS under similar conditions. However, owing to the poor solubility of starch in the carbonate buffer, the solution required heating until the starch was completely dissolved, followed by subsequent addition of DVS once the system reached room temperature. Additionally to these reference materials and the CDs-based homopolymers, heteropolymers with expected intermediate features were also synthesized by cross-linking $\alpha$ or $\beta$-CD and starch (1:1 w/w) with DVS (1:1 DVS: Glc stoichiometry).

As depicted in Table 1, there is a clear relation between the DVS:Glc stoichiometry and sulphur content (i.e., the degree of cross-linking). Thus, regardless of the polysaccharide, both homo- and hetero-polymers with stoichiometry 1:1 yielded the same amount of material with a similar degree of 
cross-linking $(23 \%-27 \% \mathrm{~S} / \mathrm{C})$. As expected, the content of sulphur for S-P0.5 (19\%) and $\boldsymbol{\alpha C D}-\mathbf{P 2}$ $(33 \%)$ is lower and higher respectively.

Table 1. Features of DVS cross-linked homo- (S-Pn and CD-Pn) and hetero-polymers (CDS/S-P).

\begin{tabular}{cccc}
\hline Polymer & $\begin{array}{c}\text { Stoichiometry } \\
\text { DVS:Glc }\end{array}$ & $\begin{array}{c}\text { Elemental } \\
\text { Analysis (\% S/C) }\end{array}$ & $\begin{array}{c}\text { Mass Resulting from } \\
\text { the Reaction (gr) }\end{array}$ \\
\hline S-P1 $^{\text {a }}$ & $1: 1$ & 26.2 & 4.1 \\
S-P0.5 $^{\text {a }}$ & $0.5: 1$ & 19.4 & 3.7 \\
$\boldsymbol{\beta C D - P 1 ~}^{\text {a }}$ & $1: 1$ & 26.7 & 3.8 \\
$\boldsymbol{\alpha C D P 2}^{\text {a }}$ & $2: 1$ & 33.3 & 5.4 \\
$\boldsymbol{\alpha C D P 1}^{\text {a }}$ & $1: 1$ & 27.2 & 3.8 \\
$\boldsymbol{\beta C D} / \mathbf{S}-\mathbf{P}$ & $1: 1^{\mathrm{b}}$ & 22.6 & 3.9 \\
$\boldsymbol{\alpha C D}^{\mathrm{S}}-\mathbf{P}$ & $1: 1^{\mathrm{b}}$ & 27.2 & 3.8 \\
\hline
\end{tabular}

${ }^{\text {a }} \mathrm{S}=\operatorname{starch} ; n=$ stoichiometry DVS:Glc ratio: $n=0.5(0.5: 1) ; n=1(1: 1), n=2(2: 1) ;{ }^{\mathrm{b}}$ Amount of Glc resulting from a 1:1 $(\mathrm{w} / \mathrm{w})$ combination of $\mathrm{CD}$ and starch.

The prepared materials were characterized by ATR-IR, powder X-ray, SEM, TGA and elemental analysis. ATR-IR spectrum are almost identical for all compounds without remarkable differences. (Supplementary Material, Figure S1) Powder X-ray diffraction patterns show a broad hump at $2 \theta=13-23^{\circ}$ that indicates that the polymers existed in a form of non-crystalline state (Supplementary Material, Figure S2). The SEM images (Figure 1: 20,000× and 10,000× magnifications) reveal the nature of the surface of the dry polymers, showing that 1:1 stoichiometry homopolymers made of $\alpha$ - or $\beta-C D$ are lobular materials that share similar features, where the degree of cross-linking exerts a clear influence. This is especially relevant for the case of $\boldsymbol{\alpha C D - P 2}$ whose surface is full of holes. The surface of the heteropolymer $\boldsymbol{\alpha C D} / \mathbf{S}-\mathbf{P}$ resembles that for S-P0.5 whereas $\boldsymbol{\beta C D} / \mathbf{S}-\mathbf{P}$ shows a more homogeneous surface.

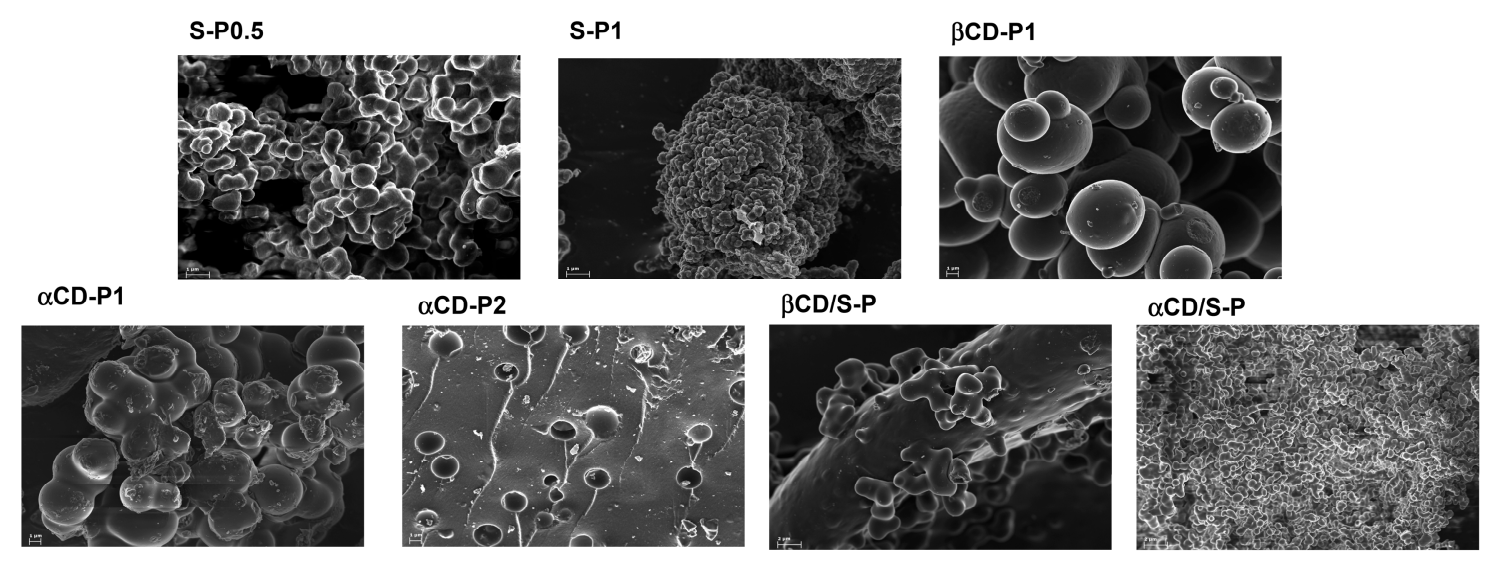

Figure 1. Electron microscopy study: Micrographs taken at 20,000× (S-P0.5, S-P1 and $\boldsymbol{\alpha C D} / \mathbf{S}-\mathbf{P})$ and $10,000 \times(\boldsymbol{\beta C D}-\mathbf{P 1}, \boldsymbol{\alpha C D}-\mathbf{P 1}, \boldsymbol{\alpha C D}-\mathbf{P} 2$ and $\boldsymbol{\beta C D} / \mathbf{S}-\mathbf{P})$ magnifications.

TGA under a nitrogen atmosphere (Supplementary material, Figure S3) shows that polymers absorb ambient moisture and thermal degradation starts around $330^{\circ} \mathrm{C}$ to reach the maximum rate between 
335.3 ${ }^{\circ} \mathrm{C}$ for S-P0.5 to $376.6{ }^{\circ} \mathrm{C}$ for $\boldsymbol{\beta C D}-\mathrm{P} 1$. At $950{ }^{\circ} \mathrm{C}$ the decomposition is not total, remaining a residual mass that ranges from $8.8 \%$ to $12.2 \%$ (Table 2).

Table 2. Main features of DVS cross-linked homo- (S-Pn and CD-Pn) and hetero-polymers (CDS/S-P) calculated from the TGA analysis in a nitrogen atmosphere.

\begin{tabular}{ccccc}
\hline Polymer & Water Content & Onset T (To) & DTG (Tp) & Residual mass \\
\hline S-P1 & $1.43 \%$ & $335{ }^{\circ} \mathrm{C}$ & $365.36{ }^{\circ} \mathrm{C}$ & $10.55 \%$ \\
S-P0.5 & $1.96 \%$ & $325{ }^{\circ} \mathrm{C}$ & $335.31{ }^{\circ} \mathrm{C}$ & $11.79 \%$ \\
$\boldsymbol{\beta C D}-P 1$ & $2.85 \%$ & $340{ }^{\circ} \mathrm{C}$ & $376.65{ }^{\circ} \mathrm{C}$ & $10.99 \%$ \\
$\boldsymbol{\alpha C D}-P 2$ & $1.75 \%$ & $330{ }^{\circ} \mathrm{C}$ & $352.20{ }^{\circ} \mathrm{C}$ & $10.38 \%$ \\
$\boldsymbol{\alpha C D}-P 1$ & $2.72 \%$ & $330{ }^{\circ} \mathrm{C}$ & $373.94{ }^{\circ} \mathrm{C}$ & $12.25 \%$ \\
$\boldsymbol{\beta C D} / \mathbf{S}-P$ & $2.25 \%$ & $335{ }^{\circ} \mathrm{C}$ & $354.06{ }^{\circ} \mathrm{C}$ & $8.77 \%$ \\
$\boldsymbol{\alpha C D} / \mathbf{S}-\mathbf{P}$ & $1.35 \%$ & $330{ }^{\circ} \mathrm{C}$ & $361.10^{\circ} \mathrm{C}$ & $9.73 \%$ \\
\hline
\end{tabular}

The analysis of the chemical species formed during the thermal decomposition reveals the presence of $\mathrm{CO}_{2}$ (signals at $3736 \mathrm{~cm}^{-1}, 3625 \mathrm{~cm}^{-1}, 2359 \mathrm{~cm}^{-1}, 2323 \mathrm{~cm}^{-1}, 668 \mathrm{~cm}^{-1}$ ), $\mathrm{CO}$ (signals at $2177 \mathrm{~cm}^{-1}$, $2116 \mathrm{~cm}^{-1}$ ), $\mathrm{SO}_{2}$ (signals at $1370 \mathrm{~cm}^{-1}, 1342 \mathrm{~cm}^{-1}, 1163 \mathrm{~cm}^{-1}$ ), $\mathrm{CH}_{4}$ (signal at $3015 \mathrm{~cm}^{-1}$ ), methanal (signals at $2894 \mathrm{~cm}^{-1}, 2861 \mathrm{~cm}^{-1}, 2801 \mathrm{~cm}^{-1}, 2744 \mathrm{~cm}^{-1}, 1745 \mathrm{~cm}^{-1}$ ) and probably ethene (signals at $3122 \mathrm{~cm}^{-1}, 3076 \mathrm{~cm}^{-1}, 2983 \mathrm{~cm}^{-1}, 1360 \mathrm{~cm}^{-1}$ ) (Figure 2).

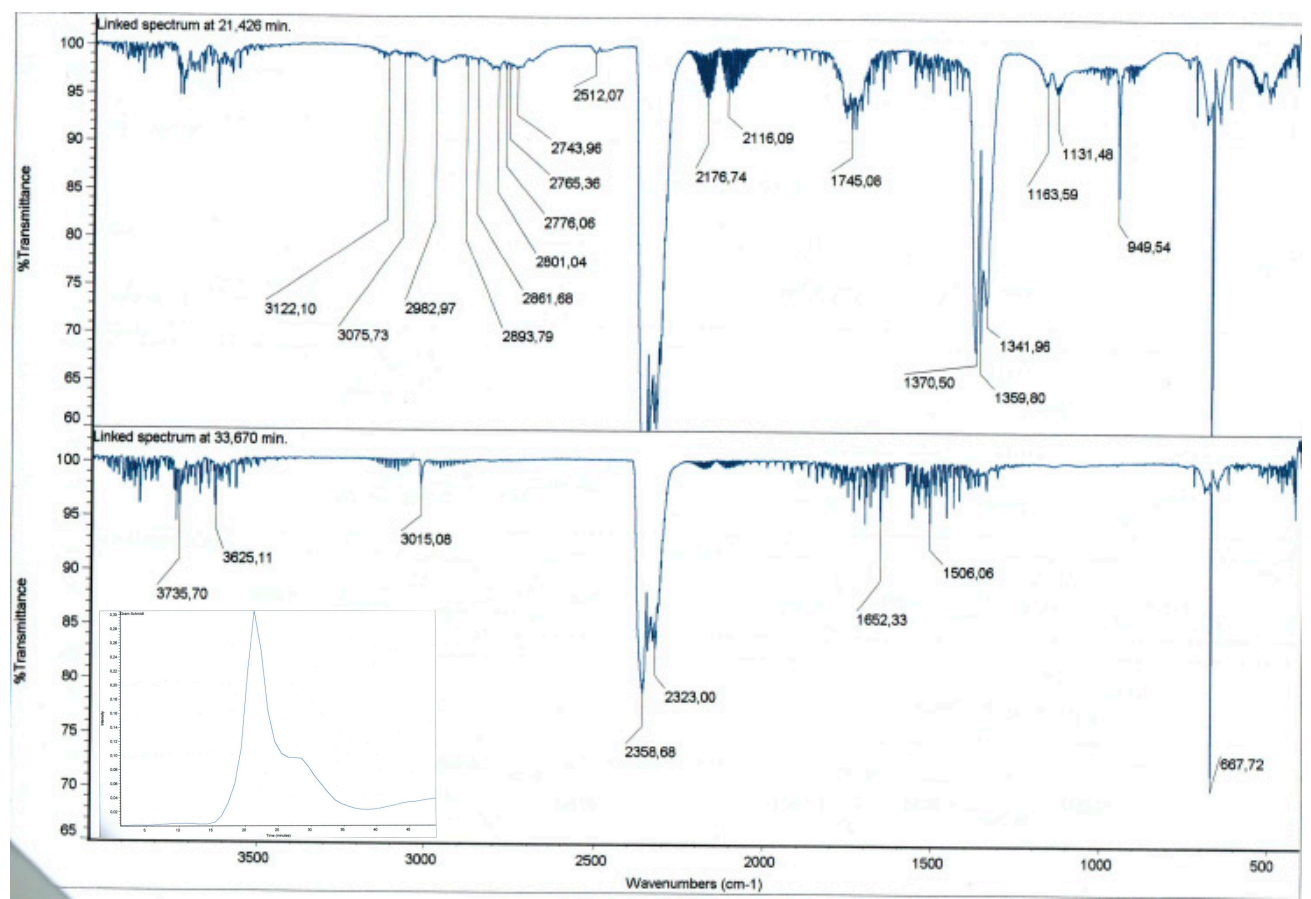

Figure 2. Representative TGA-IR result. Spectra at two single time points $21.4 \mathrm{~min}$ and 33.7 min that are shown in the Gram-Schmidt profile (insert).

As an additional characterization, the sorption of phenol (I) and 4-nitrophenol (II) (Figure 3) was studied. They were chosen as model compounds based on the importance of phenolic compounds as toxic pollutants commonly encountered in trace quantities in aqueous effluents from various manufacturing processes such as oil refineries, coke plants, and phenolic resin plants. In addition, the 
binding of phenol and 4-nitrophenol to cyclodextrin has been studied by other authors [27-32] and the thermodynamics of the inclusion complexes are well known [33].

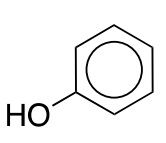

I

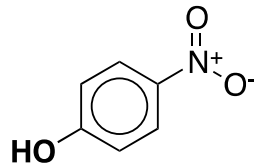

II

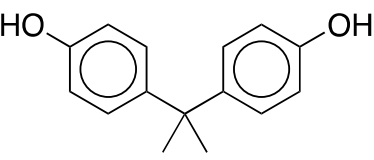

III

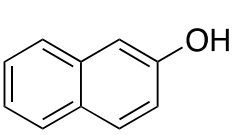

IV

Figure 3. Model phenolic compounds phenol (I) and 4-nitrophenol (II) and representative phenolic pollutants bisphenol-A (III) and $\beta$-naphthol (IV).

Prior to the study of the sorbent capacities of the synthesized CDPs towards these compounds, the kinetics of the sorption process were investigated to ascertain the time required to reach the equilibrium in that dynamic process. In these assays, the sorption capacity of the polymers was evaluated by measuring the remaining amounts of those compounds in solution versus the contact time when a fixed concentration (100 ppm) of the organic pollutants was stirred in the presence of an identical amount of the different polymers. The data showed that a plateau is reached after only 15-30 min independently of the polymer structure, time that is indicative of fast sorption kinetics in all cases.

The sorption capacities were next studied by adding identical volumes of solutions of the model phenolic pollutants with concentrations ranging from $20-5000 \mathrm{ppm}$ to a fixed amount (100 $\mathrm{mg}) \mathrm{of}$ these materials (Table 3). The quantity of the pollutant adsorbed was determined by measuring the UV-Vis absorption in the solution. Data were fitted to the linearized forms of the Langmuir isotherm $\left(\mathrm{C}_{\mathrm{e}} / \mathrm{Cq}=1 / \mathrm{K}_{\mathrm{L}}+1 / \mathrm{q}_{\max } \times \mathrm{Ce}\right)$ and the Freundlich isotherm $\left(\mathrm{LnCq}=\mathrm{LnK}_{\mathrm{F}}+(1 / \mathrm{N}) \times \mathrm{LnCe}\right)$ (Supplementary Material, Figures S4 and S5). It is important to recall that the Langmuir model assumes a monolayer sorption of solute on homogeneous sorption sites, being $\mathrm{Ce}$ and $\mathrm{Cq}$ the concentration of solute at the equilibrium in the solution and in the polymer, respectively, $\mathrm{K}_{\mathrm{L}}$ the bonding energy constant and $\mathrm{q}_{\max }$ the sorption maximum. By contrast, the Freundlich model relies on an empirical expression that can be applied to non-ideal sorption on dissimilar surfaces along with multilayer absorption, being Ce concentration of solute at the equilibrium in the solution, $\mathrm{K}_{\mathrm{F}}$ the capacity factor and $\mathrm{N}$ is a parameter related to the heterogeneity of the system [34].

The determination coefficients reveal that the process of sorption is better described by the isotherm of Freundlich (Table 3), particularly for the polymers obtained by cross-linking of starch that showed low affinity for both phenol and 4-nitrophenol when compared to the other polymers. In general, the degree of cross-linking does not seem to play a significant influence on the properties of the material. As expected, Langmuir and Freundlich fittings demonstrate, first, that the homo-CDPs are the best materials. In addition, the results with the hetero-CDPs are outstanding when compared to those obtained from starch, highlighting the role of $\mathrm{CD}$ in the sorption, and suggesting the formation of inclusion complexes that may explain the poor performance of the cross-linked starch. According to the thermodynamic parameters reported in literature, $\alpha-C D$ and $\beta-C D$ bind more strongly to phenol and 4-nitrophenol, respectively [33] and this is in full agreement with the $\mathrm{K}_{\mathrm{L}}$ values estimated for the heteropolymers. However, it is also apparent that $\alpha-\mathrm{CD}$ homopolymer has the highest affinity and capacity factor for 4-nitrophenol and this discrepancy may be rationalized considering that the sorption process on $\mathrm{CD}$ in solution is different to that when it forms an insoluble polymer. 


\subsection{Sorption of Representative Phenolic Pollutants $\beta$-Naphthol (III) and Bisphenol-A (IV)}

As discussed above phenolic compounds were chosen as model systems because they are important toxic pollutants. Due to increasingly stringent restrictions for these pollutants, a panel of diverse techniques has been proposed for their removal: liquid-liquid extraction, activated carbon, anion-exchange resins, micellar-enhanced ultrafiltration, use of membranes by pervaporation, and also the use of CDPs. In the reported cases related with the use of CDPs for the removal of phenolic compounds, CDs has been cross-linked by using EPI and diisocyanates as cross-linker reagents having generally showed good removal efficiency.

In order to test the performance of the polymers they were assayed with two representative phenolic pollutants with larger molecular dimensions than the models compounds: bisphenol A (III) and $\beta$-naphthol (IV) (Figure 3). Bisphenol A (BPA) is used in the manufacture of epoxy resins and polycarbonate. BPA has been identified as an endocrine-disrupting chemical by the US Environmental Protection Agency, and the World Wide Fund for Nature [35,36] that affects the reproductive behaviour of both humans and animals and induces various diseases including cancer [37]. The poor solubility of this compound makes BPA difficult to remove and it bioaccumulates [38]. Naphthalene derivatives with substituents at position 2 are usually more toxic than those at position 1, therefore, $\beta$-naphthol is listed among top priority contaminants [39]. This compound biodegrades very slowly and, due to its toxicity, industrial wastewater containing 2-naphthol must be treated before it is reused or discharged to the environment.

As these compounds are poorly water-soluble, $\mathrm{MeOH}$ and DMSO were used as co-solvents (10\% $\mathrm{v} / \mathrm{v}$ ) and the solutions were prepared in a more restricted concentration range (20-1000 ppm). Considering that the results from the sorption of phenol and 4-nitrophenol suggest that the degree of cross-linking plays a minor role (Table 3), only polymers with 1:1 DVS:Glc stoichiometry were tested. The sorption capacities were evaluated following the analytical methodology described above and the main parameters of the isotherms are depicted in Table 4. In the present case, the BPA sorption process is, in general, better described by a Freundlich isotherm, being the polymer based on cross-linked starch the material that shows the poorest performance. However, the determination coefficients reveal that data of the sorption from solutions containing $10 \%$ (v/v) $\mathrm{MeOH}$ on $\boldsymbol{\beta C D}-\mathbf{P 1}, \boldsymbol{\alpha C D}-\mathbf{P 1}$ and $\boldsymbol{\beta C D} / \mathbf{S}-\mathbf{P}$ also fit very well the Langmuir isotherm, suggesting that the process can be described as a sorption onto a monolayer of homogeneous sites. The estimated maximum sorption is in the range of the 84 $\mathrm{mg} / \mathrm{g}$ described for cross-linked CD with EPI [40], except for $\boldsymbol{\alpha C D}$-P1 which is unexpectedly high because according to bibliography the improvement in the solubility of BPA in water by addition of hydroxypropyl- $\alpha-C D$ is worse than that by hydroxypropyl- $\beta-C D$ [41]. This result may attributed to the polymeric (i.e., multivalent) nature of $\boldsymbol{\alpha C D}$-P1. Interestingly, ${ }^{1} \mathrm{H}-\mathrm{NMR}$ studies on the inclusion complexes of BPA with $\alpha-\mathrm{CD}$ did not find any signal that could be assigned to the BPA protons [42] and this may be rationalized as the formation of a week inclusion complex that is in full agreement with the low $\mathrm{K}_{\mathrm{L}}$ values estimated for the polymers containing $\alpha-\mathrm{CD}$. The isotherm of Langmuir can be used to describe the sorption of BPA onto $\boldsymbol{\beta C D - P 1}$ and allows the analysis of the co-solvent on the process: the estimated maximum capacity remains constant whereas the bonding energy constant diminishes when the co-solvent is polar and aprotic. 
Table 3. Freundlich and Langmuir parameters for the sorption of phenol (I) and 4-nitrophenol (II) (20-5000 ppm solutions in water) on the DVS cross-linked homo- (S-Pn and CD-Pn) ${ }^{\text {a }}$ and heteropolymers (CDS/S-Pn) ${ }^{\text {a }}$ (100 mg). (Supplementary Material, Figures S4 and S5).

\begin{tabular}{|c|c|c|c|c|c|c|c|c|c|c|c|c|c|c|c|}
\hline \multirow{2}{*}{ Isotherm } & \multirow{2}{*}{ Parameter } & \multicolumn{2}{|c|}{ S-P1 ${ }^{a}$} & \multicolumn{2}{|c|}{ S-P0.5 ${ }^{\mathrm{a}}$} & \multicolumn{2}{|c|}{$\beta_{C D D-P 1}{ }^{a}$} & \multicolumn{2}{|c|}{$\alpha C D P 2^{a}$} & \multicolumn{2}{|c|}{$\alpha C D P 1^{a}$} & \multicolumn{2}{|c|}{$\beta C D / S-P^{a}$} & \multicolumn{2}{|c|}{$\alpha C D / S-P^{a}$} \\
\hline & & I & II & I & II & I & II & I & II & I & II & I & II & I & II \\
\hline \multirow{3}{*}{ Freundlich } & $\mathrm{R}^{2}$ & 0.993 & 0.999 & 0.983 & 0.987 & 0.993 & 1.000 & 0.992 & 0.998 & 0.986 & 0.994 & 0,997 & 0.999 & 0.997 & 0.999 \\
\hline & $\mathrm{N}$ & 0.887 & 0.999 & 0.857 & 1.077 & 1.507 & 1.326 & 1.430 & 1.515 & 1.863 & 1.575 & 1.1248 & 1.496 & 1.445 & 1.319 \\
\hline & $\mathrm{K}_{\mathrm{F}} \times 10^{3}$ & 2.151 & 19.111 & 1.206 & 23.004 & 199.149 & 340.003 & 243.777 & 627.696 & 623.005 & 902.217 & 56.067 & 404.501 & 146.413 & 193.438 \\
\hline \multirow{3}{*}{ Langmuir } & $\mathrm{R}^{2}$ & 0.088 & 0.063 & 0.383 & 0.010 & 0.844 & 0.816 & 0.895 & 0.867 & 0.858 & 0.921 & 0.771 & 0.817 & 0.807 & 0.749 \\
\hline & $\mathrm{K}_{\mathrm{L}}$ & $\mathrm{n} / \mathrm{a}$ & $\mathrm{n} / \mathrm{a}$ & $\mathrm{n} / \mathrm{a}$ & $\mathrm{n} / \mathrm{a}$ & 0.040 & 0.119 & 0.064 & 0,150 & 0.066 & 0.225 & 0.021 & 0.083 & 0.032 & 0.060 \\
\hline & $\mathrm{q}_{\max }(\mathrm{mg} / \mathrm{g})$ & $\mathrm{n} / \mathrm{a}$ & $\mathrm{n} / \mathrm{a}$ & $\mathrm{n} / \mathrm{a}$ & $\mathrm{n} / \mathrm{a}$ & 67.788 & 200.275 & 97.362 & 148.723 & 61.667 & 148.643 & 78.724 & 135.896 & 66.112 & 164.027 \\
\hline
\end{tabular}

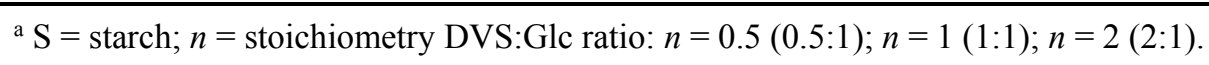

Table 4. Freundlich and Langmuir parameters for the sorption of bisphenol A (III) and $\beta$-naphthol (IV) (20-1000 ppm solutions in water and either 10\% methanol or 10\% DMSO) on the DVS cross-linked homo- (S-Pn and CD-Pn) ${ }^{a}$ and hetero-polymers (CDS/S-P1) (1:1 DVS:Glc stoichiometry) (100 mg). (Supplementary Material, Figures S6-S9).

\begin{tabular}{|c|c|c|c|c|c|c|c|c|c|c|c|c|}
\hline \multirow{2}{*}{ Solvent } & \multirow{2}{*}{ Isotherm } & \multirow{2}{*}{ Parameter } & \multicolumn{2}{|c|}{ S-P1 ${ }^{a}$} & \multicolumn{2}{|c|}{${ }_{\beta C D-P 1}{ }^{a}$} & \multicolumn{2}{|c|}{$\alpha C D P 1{ }^{a}$} & \multicolumn{2}{|c|}{$\beta C D / S-P^{a}$} & \multicolumn{2}{|c|}{$\alpha C D / S-P^{a}$} \\
\hline & & & III & IV & III & IV & III & IV & III & IV & III & IV \\
\hline \multirow{6}{*}{$\mathrm{MeOH}$} & \multirow{3}{*}{ Freundlich } & $\mathrm{R}^{2}$ & 0.998 & 0.998 & 0.970 & 0.998 & 0.995 & 0.998 & 0.959 & 0.996 & 0.993 & 0.993 \\
\hline & & $\mathrm{N}$ & 0.620 & 1.016 & 1.554 & 1.457 & 1.164 & 1.451 & 1.542 & 1.383 & 1.065 & 1.240 \\
\hline & & $\mathrm{K}_{\mathrm{F}} \times 10^{3}$ & 57.487 & 66.497 & 1417.224 & 725.786 & 339.596 & 752.014 & 1631.827 & 390.589 & 199.708 & 240.918 \\
\hline & \multirow{3}{*}{ Langmuir } & $\mathrm{R}^{2}$ & 0.578 & 0.308 & 0.972 & 0.883 & 0.980 & 0.838 & 0.966 & 0.840 & 0.790 & 0.874 \\
\hline & & $\mathrm{K}_{\mathrm{L}}$ & $\mathrm{n} / \mathrm{a}$ & $\mathrm{n} / \mathrm{a}$ & 0.707 & 0.295 & 0.238 & 0.313 & 0.856 & 0.169 & 0.173 & 0.136 \\
\hline & & $\mathrm{q}_{\max }(\mathrm{mg} / \mathrm{g})$ & $\mathrm{n} / \mathrm{a}$ & $\mathrm{n} / \mathrm{a}$ & 69.153 & 72.826 & 119.317 & 75.043 & 76.231 & 56.642 & 190.905 & 67.717 \\
\hline \multirow{6}{*}{ DMSO } & \multirow{3}{*}{ Freundlich } & $\mathrm{R}^{2}$ & 0.997 & 0.997 & 0.984 & 0.996 & 0.995 & 0.992 & 0.944 & 1.000 & 0.999 & 0.994 \\
\hline & & $\mathrm{N}$ & 0.927 & 1.068 & 1.459 & 1.298 & 1.066 & 1.291 & 1.290 & 1.234 & 1.050 & 1.159 \\
\hline & & $\mathrm{K}_{\mathrm{F}} \times 10^{3}$ & 32.998 & 43.205 & 865.455 & 309.468 & 159.151 & 360.703 & 598.517 & 161.121 & 105.484 & 117.209 \\
\hline & \multirow{3}{*}{ Langmuir } & $\mathrm{R}^{2}$ & 0.271 & 0.872 & 0.947 & 0.902 & 0.838 & 0.944 & 0.850 & 0.822 & 0.747 & 0.944 \\
\hline & & $\mathrm{K}_{\mathrm{L}}$ & $\mathrm{n} / \mathrm{a}$ & 0.035 & 0.403 & 0.135 & 0.135 & 0.192 & 0.341 & 0.838 & 0.091 & 0.076 \\
\hline & & $\mathrm{q}_{\max }(\mathrm{mg} / \mathrm{g})$ & $\mathrm{n} / \mathrm{a}$ & 80.137 & 69.844 & 66.944 & 185.832 & 67.727 & 88.838 & 0.838 & 256.673 & 66.944 \\
\hline
\end{tabular}

${ }^{\text {a }} \mathrm{S}=\operatorname{starch} ; n=1$ (1:1) stoichiometry DVS:Glc ratio. 
Data for the sorption of $\beta$-naphthol follow the expected trend. They can be fitted to the Freundlich isotherm and the polymer obtained by crosslinking of starch shows the worst performance, highlighting the importance of the formation of inclusion complexes (Table 4). The Langmuir isotherm can describe the sorption of $\beta$-naphthol in $10 \%$ DMSO on DVS cross-linked $\alpha, \beta$-CD-polymers, suggesting that there is not a clear influence of the size of the $\mathrm{CD}$ on the maximum estimated capacity and on the bonding energy constant.

\subsection{Sorption of Bioactive Compounds}

As mentioned above, CDPs are attractive materials in the medicinal and pharmaceutical field as encapsulating agents with a high potential in the formulation of drugs and biopharmaceuticals. To evaluate these inclusion capabilities in the case of the DVS cross-linked CDPs a representative steroid hormone, progesterone (V), and a naturally bioactive phenolic compound, curcumin (VI), were chosen as archetypal models (Figure 4).
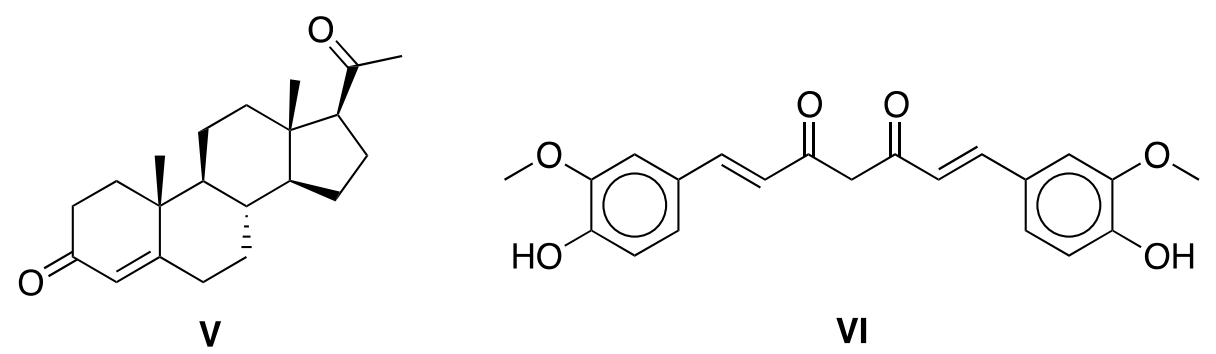

Figure 4. Archetypal drug for encapsulation assays: Progesterone (V) and curcumin (VI)

Progesterone is a lipophilic drug used in menopausal hormone replacement therapy and reproductive control functions in which oral delivery is limited due to its poor aqueous solubility. In addition, progesterone exhibits a low tolerance when administered in high doses. Efforts to overcome these undesirable properties have led to the development of suitable carriers to facilitate the drug administration to the target site while optimizing delivery amount over a predetermined period [43]. Among the CD-based systems used for delivery progesterone different approaches have been undertaken such as the formation of nanoparticles from amphiphilic CDs [44-46], incorporation of progesterone-CD ICs into ternary systems [solid lipid nanospheres [47], bovine serum albumin nanospheres [48], polymeric nanoparticles [49] and hydrophilic polymers-chitosan [50], PEG [51,52] and others [53] and molecular imprinting of CDPs [54].

Curcumin is a natural yellow phenolic antioxidant of low toxicity that shows pharmacological activity on various diseases such as cancer, cardiovascular disease, inflammatory bowel syndrome, wound healing, Alzheimer's disease, rheumatoid arthritis, and diabetes. Despite these advantages, applications of curcumin are limited because of its low bioavailability, rapid degradation and metabolism. Many studies directed to overcome these problems have been focused on the development of nanopreparations enabling encapsulation solutions [55], and, nowadays, liposomes, polymeric nanoparticles and micelles, conjugates, peptide carriers, solid dispersions, lipid nanoparticles, emulsions, and also CDs have been explored for these purposes [56-58]. The application of CDs as 
nano-carrier systems has been demonstrated to be a viable choice either by the use of native or chemical modified CDs as well as by the application of a $\beta$-CDPs in one reported case [59].

\subsubsection{Sorption of Progesterone (V)}

To study the encapsulation of progesterone by the DVS cross-linked CDPs, solutions of those compounds using $\mathrm{MeOH}(10 \%)$ as co-solvent (10\%) were prepared considering their low water solubility and the results obtained for the phenolic pollutants. In these conditions, the highest solubility attained was $50 \mathrm{ppm}$ and, on this basis, the solutions ranged from 5 to $50 \mathrm{ppm}$ (Table 5). The encapsulation capacities of the polymers with 1:1 DVS:Glc stoichiometry were assayed by the batch methodology described above. As shown in Table 5 experimental data fit the Freundlich isotherm and the estimated values of $\mathrm{K}_{\mathrm{F}}$ point to $\boldsymbol{\beta C D} / \mathbf{S}-\mathbf{P}$ as the most promising encapsulating agent and suggest the suitability of the carbohydrate in the rank order $\beta-\mathrm{CD}>\operatorname{starch}>\alpha-\mathrm{CD}$. The Langmuir isotherm can be applied to $\boldsymbol{\beta C D}-\mathbf{P 1}$ and $\boldsymbol{\beta C D / S - P}$ and allows the evaluation of the contribution of the starch. Interestingly the better values of both $\mathrm{K}_{\mathrm{L}}$ and $\mathrm{q}_{\max }$ for $\boldsymbol{\beta C D / S - P}$ confirm the positive contribution of the starch to the encapsulating properties of the heteropolymers.

Table 5. Freundlich and Langmuir parameters for the sorption of progesterone (V) (5-50 ppm in methanol:water 1:9) and curcumin (VI) (2-16.7 mM in ethanol) on the DVS cross-linked homo- (S-P1 and CD-P1) and heteropolymers (CDS/S-P1) (1:1 DVS:Glc stoichiometry) (100 mg and $125 \mathrm{mg}$ respectively). (Supplementary Material, Figures S10 and S11).

\begin{tabular}{|c|c|c|c|c|c|c|c|c|}
\hline \multirow{2}{*}{ Isotherm } & \multirow{2}{*}{ Parameter } & \multirow{2}{*}{$\begin{array}{l}\text { S-P1 } \\
\mathbf{V}\end{array}$} & \multicolumn{2}{|c|}{ BCD-P1 } & \multirow{2}{*}{$\frac{\alpha C D-P 1}{V}$} & \multicolumn{2}{|c|}{ 及CD/S-P } & \multirow{2}{*}{$\frac{\alpha C D / S-P}{V}$} \\
\hline & & & $\mathbf{V}$ & VI & & $\mathbf{V}$ & VI & \\
\hline \multirow{3}{*}{ Freundlich } & $\mathrm{R}^{2}$ & 0.992 & 0.993 & 0.974 & 0.992 & 0.994 & 0.999 & 0.981 \\
\hline & $\mathrm{N}$ & 1.171 & 1.222 & 1.036 & 1.118 & 1.214 & 0.985 & 1.198 \\
\hline & $\mathrm{K}_{\mathrm{F}} \times 10^{3}$ & 114.040 & 291.825 & $10,411.744$ & 84.983 & 442.241 & 8.915 & 110.339 \\
\hline \multirow{3}{*}{ Langmuir } & $\mathrm{R}^{2}$ & 0.751 & 0.972 & 0.275 & 0.755 & 0.974 & 0.107 & 0.647 \\
\hline & $\mathrm{K}_{\mathrm{L}}$ & 0.099 & 0.281 & na & 0.077 & 0.452 & na & 0.093 \\
\hline & $\mathrm{q}_{\max }(\mathrm{mg} / \mathrm{g})$ & 5.807 & 6.645 & na & 6.480 & 7.928 & na & 5.074 \\
\hline
\end{tabular}

\subsubsection{Sorption of Curcumin}

The study of the encapsulation of curcumin was limited to the materials containing $\beta$-CD and 1:1 Glc:DVS stoichiometry. As depicted in Table 5 data could only be fitted to the Freundlich isotherm, suggesting that the process involves a non-ideal sorption on dissimilar surfaces and/or multilayer sorption. The value of $\mathrm{K}_{\mathrm{F}}$ estimated for $\boldsymbol{\beta C D}-\mathbf{P 1}$ is several orders of magnitude higher than that for $\boldsymbol{\beta C D} / \mathbf{S}-\mathbf{P}$. This difference may be rationalized on the basis of the proposed structure of the 2:1 $\mathrm{CD}$ :curcumin inclusion complex [60] where the distance between $\mathrm{CD}$ plays a critical role in the stability of the complex, in $\boldsymbol{\beta C D}-\mathbf{P 1}$ being at more favourable positions than in $\boldsymbol{\beta C D / S - P}$ to yield the formation of the $2: 1$ ICs. 


\section{Experimental Section}

\subsection{Materials}

Native cyclodextrins $\alpha$ and $\beta$-cyclodextrin ( $\alpha$ - and $\beta$-CD) with $95 \%$ degree of purity were bought from TCI Europa N.V. (Madrid, Spain). Divinyl sulfone (DVS) with 97\% degree of purity was purchased from AlfaAesar (Karlsruhe, Germany) Phenolic compounds (phenol, 4-nitrophenol, bisphenol, 2-naphthol), progesterone and curcumin were acquired from Sigma-Aldrich (Madrid, Spain). Ethanol, methanol and dimethyl sulfoxide were of analytical grade reagents (Panreac Quimica, Barcelona, Spain) and_were used without further purification.

\subsection{Synthesis of DVS Cross-Linked Homo-Polymers (S-Pn and CD-Pn)}

A solution of the corresponding oligo- $(\alpha-$ or $\beta-\mathrm{CD})$ or polysaccharide (starch) was prepared by dissolving these materials in carbonate buffer $(0.5 \mathrm{M}, \mathrm{pH} 12,150 \mathrm{~mL})$ under magnetic stirring at room temperature, for the case of $\alpha$ - or $\beta-\mathrm{CD}$, or by heating under reflux (15-20 min) for the case of starch. After magnetic stirring for additional $30 \mathrm{~min}$, DVS was added to yield 0.5:1, 1:1 or 2:1 DVS:glucose (DVS:Glc) ( $n=0.5,1$ or 2 , respectively) stoichiometric molar ratios. The reaction was maintained for 7-8 h giving as a result a white solid powder that precipitates from the reaction media. In order to remove unreacted components and neutralize the $\mathrm{pH}$, the resulting polymer was filtered and thoroughly washed with deionized water $(4 \mathrm{~L})$ and then with $\mathrm{MeOH}(0.5 \mathrm{~L})$ and diethyl ether $(0.25 \mathrm{~L})$. The resulting cross-linked polymer (S-Pn or CD-Pn) was dried in vacuo for $18 \mathrm{~h}$ at $50{ }^{\circ} \mathrm{C}[26]$.

\subsection{Synthesis of DVs Cross-Linked Hetero-CDPs (CDS/S-P)}

A suspension of starch $(1.5 \mathrm{~g})$ in carbonate buffer $(0.5 \mathrm{M}, \mathrm{pH} 12,150 \mathrm{~mL})$ was heated under reflux until complete solubilization (15-20 min). The solution was left to reach room temperature and $\alpha$ - or $\beta-C D(1.5 \mathrm{~g})$ was added and dissolved under magnetic stirring. The stirring was continued for $30 \mathrm{~min}$ prior to the addition of DVS $(2 \mathrm{~mL})$ and maintained during the cross-linking reaction $(7-8 \mathrm{~h})$ giving as a result a white solid powder that precipitates from the reaction media. In order to remove unreacted components and neutralize the $\mathrm{pH}$, the resulting polymer was filtered and thoroughly washed with deionized water, $\mathrm{MeOH}$ and diethyl ether. The resulting cross-linked starch-CD polymer CDS/S-P was dried in vacuo for $18 \mathrm{~h}$ at $50{ }^{\circ} \mathrm{C}$ [26].

\subsection{Characterization of DVS Cross-Linked Polymers}

CHNS analyses were determined with a Thermo Scientific Flash 2000 elemental analyzer (Thermo Scientific, Madrid, Spain). Electron microscopy examination was performed on samples covered with gold using a sputter coater (SEMPREP2, Technoorg Linda LTD, Budapest, Hungary) and electron micrographs were taken with a S-510C scanning electron microscope at $3 \mathrm{kV}$ (Hitachi High Technologies Europe GmbH, Krefeld, Germany). X-ray diffraction was carried out on a Pw1710/00 diffractometer (Philips, Madrid, Spain) using $\mathrm{Cu} \mathrm{K} \alpha$ radiation. The operation voltage and current were $40 \mathrm{kV}$ and $40 \mathrm{~mA}$ respectively. Data were collected from $3^{\circ}$ to $80^{\circ}$ with a $0.04^{\circ}$ step and $0.4 \mathrm{~s}$ of integration. Data acquisition and processing were carried out with the Xpowder diffraction software [61]. 
IR spectra were recorded on a Spectrum Two (Perkin-Elmer, Madrid, Spain) and TGA analysis was carried out on dried polymers using a Shimadzu TGA-50H instrument (Shimadzu, Madrid, Spain) coupled to a Nicolet 550 IR-FT spectrometer (Thermo Scientific, Madrid, Spain). Samples were heated up to $950{ }^{\circ} \mathrm{C}$ in nitrogen at a heating rate of $20^{\circ} \mathrm{C}$.

\subsection{Sorption Experiments}

DVS cross-linked homo- or heteropolymer $(100 \mathrm{mg})$ was added to different solutions $(10 \mathrm{~mL}) \mathrm{of}$ the phenolic compound or progesterone in water (for phenol or 4-nitrophenol, 20-5000 ppm) or 10\% aqueous $\mathrm{MeOH}$ or DMSO (for $\beta$-naphthol, bisphenol A, 20-1000 ppm), in methanol for progesterone $(5-50 \mathrm{ppm})$ or in absolute ethanol for curcumin $(2-16.7 \mathrm{mM})$. The resulting suspensions were stirred in an orbital stirring table at $180 \mathrm{rpm}$ for $3 \mathrm{~h}$ at room temperature. After this time, an aliquot of the starting solution and the treated solution were filtered in a syringe containing a regenerated cellulose filter (porous size $0.2 \mu \mathrm{m}$ ). The concentration of the filtered solutions was measured by UV/vis absorption in a Spectronic Unicam Heגios instrument (Thermo Fisher Scientific, Waltham, MA, USA) at $317 \mathrm{~nm}$ (phenol and 4-nitrophenol, $328 \mathrm{~nm}$ ( $\beta$-naphthol, bisphenol A), $249 \mathrm{~nm}$ (progesterone) or at both 422 and $467 \mathrm{~nm}$ (curcumin).

\section{Conclusions}

Divinyl sulfone is an efficient cross-linking agent for the synthesis of aqueous insoluble cyclodextrin-based polymers (CDPs) and other insoluble polymers from polysaccharides, providing that the reaction is carried out at an alkaline $\mathrm{pH}$. The degree of cross-linking exerts a clear influence on the surface of the material, whereas it plays a minor role on the formation of the inclusion complexes. In general, inclusion experiments on the CDPs are better described by the Freundlich isotherm although an important number of them can also be fitted to the Langmuir isotherm with $\mathrm{R}^{2} \geq 0.9$, suggesting a sorption onto a monolayer of homogeneous sites. The results demonstrate the versatility of CDPs and highlight the important role of the CDs, supporting a sorption process based on the formation of inclusion complexes that may explain the poor performance of the cross-linked starch used as reference.

\section{Supplementary Materials}

Supplementary materials can be accessed at: http://www.mdpi.com/1420-3049/20/03/3565 /s1.

\section{Acknowledgments}

The authors acknowledge the Ministerio de Ciencia and Innovacion for financial support (Grant CTQ2011-29299-CO2-01). Mahmoud acknowledges Erasmus Mundus Program (ELEMENT) for financial funding. J. Hutton is acknowledged for English supervision. 


\section{Author Contributions}

FSG, JMS, FJLJ and FHM conceived the study and oversaw the analysis. JMS and MAAE carried out the experimental work. FJLJ and FHM were responsible for the draft of the manuscript. All authors read and approved the final manuscript.

\section{Conflicts of Interest}

The authors declare no conflict of interest.

\section{References}

1. Van de Manakker, F.; Vermonden, T.; van Nostrum, C.F.; Hennink, W.E. Cyclodextrin-Based Polymeric Materials: Synthesis, Properties, and Pharmaceutical/Biomedical Applications. Biomacromolecules 2009, 10, 3157-3175.

2. Landy, D.; Mallard, I.; Ponchel, A.; Monflier, E.; Fourmentin, S. Remediation technologies using cyclodextrins: An overview. Environ. Chem. Lett. 2012, 10, 225-237.

3. Landy, D.; Mallard, I.; Ponchel, A.; Monflier, E.; Fourmentin, S. Cyclodextrins for Remediation Technologies. In Environmental Chemistry for a Sustainable World; Lichtfouse, E., Schwarzbauer, J., Robert, D., Eds.; Springer: Dondrecht, The Netherlands, 2012; pp. 47-81.

4. Heidel, J.D.; Schluep, T. Cyclodextrin-Containing Polymers: Versatile Platforms of Drug Delivery Materials. J. Drug Deliv. 2012, 2012, doi: 10.1155/2012/262731.

5. Zhou, J.; Ritter, H. Cyclodextrin functionalized polymers as drug delivery systems. Polym. Chem. 2010, 1, 1552-1559.

6. Crini, G. Recent developments in polysaccharide-based materials used as adsorbents in wastewater treatment. Prog. Polym. Sci. 2005, 30, 38-70.

7. Crini, G.; Morcellet, M. Synthesis and applications of adsorbents containing cyclodextrins. J. Sep. Sci. 2002, 25, 789-813.

8. Dabrowski, A. Adsorption: From theory to practice. Adv. Colloid Interface Sci. 2001, 93, 135-224.

9. Palem, C.R.; Siva, C.K.; Subrahmanyam, P.V.R.S.; Rao, Y.M. Cyclodextrins and their Derivatives in Drug Delivery: A Review. Curr. Trends Biotechnol. Pharm. 2012, 6, 255-279.

10. Ali, N.; Harikumar, S.L.; Kaur, A. Cyclodextrins: An excipient tool in drug delivery. Int. Res. J. Pharm. 2012, 3, 44-50.

11. Zhang, J.; Ma, P.X. Cyclodextrin-based supramolecular systems for drug delivery: Recent progress and future perspective. Adv. Drug Deliv. Rev. 2013, 65, 1215-1233.

12. Rasheed, A. Cyclodextrins as Drug Carrier Molecule: A Review. Sci. Pharm. 2008, 76, 567-598.

13. Lipinski, C.A. Drug-like properties and the causes of poor solubility and poor permeability. J. Pharmacol. Toxicol. 2001, 44, 235-249.

14. Zhang, H.; Tan, T.; Hetenyi, C.; Lv, Y.; van der Spoel, D. Cooperative Binding of Cyclodextrin Dimers to Isoflavone Analogues Elucidated by Free Energy Calculations. J. Phys. Chem. C 2014, $118,7163-7173$.

15. Li, J.; Loh, X.J. Cyclodextrin-based supramolecular architectures: Syntheses, structures, and applications for drug and gene delivery. Adv. Drug Deliv. Rev. 2008, 60, 1000-1017. 
16. Morin-Crini, N.; Crini, G. Environmental applications of water-insoluble $\beta$-cyclodextrinepichlorohydrin polymers. Prog. Polym. Sci. 2013, 38, 344-368.

17. Yamasaki, H.; Makihata, Y.; Fukunaga, K. Preparation of crosslinked $\beta$-cyclodextrin polymer beads and their application as a sorbent for removal of phenol from wastewater. J. Chem. Technol. Biotechnol. 2008, 83, 991-997.

18. Ozmen, E.Y.; Sezgin, M.; Yilmaz, A.; Yilmaz, M. Synthesis of $\beta$-cyclodextrin and starch based polymers for sorption of azo dyes from aqueous solutions. Bioresour. Technol. 2008, 99, 526-531.

19. Zhao, D.; Zhao, L.; Zhu, C.-S.; Huang, W.-Q.; Hu, J.-L. Water-insoluble $\beta$-cyclodextrin polymer crosslinked by citric acid: synthesis and adsorption properties toward phenol and methylene blue. J. Incl. Phenom. Macrocycl. Chem. 2009, 63, 195-201.

20. Zhao, D.; Zhao, L.; Zhu, C.; Tian, Z.; Shen, X. Synthesis and properties of water-insoluble $\beta$-cyclodextrin polymer crosslinked by citric acid with PEG-400 as modifier. Carbohydr. Polym. 2009, 78, 125-130.

21. Bednarz, S.; Lukasiewicz, M.; Mazela, W.; Pajda, M.; Kasprzyk, W. Chemical structure of poly( $\beta$-cyclodextrin-co-citric acid). J. Appl. Polym. Sci. 2011, 119, 3511-3520.

22. Forristal, I. The chemistry of a, $\beta$-unsaturated sulfoxides and sulfones: an update. J. Sulfur Chem. 2005, 26, 163-195.

23. Meadows, D.C.; Gervay-Hague, J. Vinyl sulfones: Synthetic preparations and medicinal chemistry applications. Med. Res. Rev. 2006, 26, 793-814.

24. Morales-Sanfrutos, J.; Lopez-Jaramillo, J.; Ortega-Munoz, M.; Megia-Fernandez, A.; Perez-Balderas, F.; Hernandez-Mateo, F.; Santoyo-Gonzalez, F. Vinyl sulfone: A versatile function for simple bioconjugation and immobilization. Org. Biomol. Chem. 2010, 8, 667-675.

25. Lopez-Jaramillo, F.J.; Hernandez-Mateo, F.; Santoyo-Gonzalez, F. Vinyl sulfone: A Multi-purpose Function in Proteomics. In Integrative Proteomics; Eastwood Leung, H.-C., Ed.; InTech: Rijeka, Croatia, 2012, pp. 301-326.

26. Santoyo-González, F.; Hernandez-Mateo, F.; Morales-Sanfrutos, J. Polymeric Adsorbents Based on Polysaccharides and Cyclodextrins for Water Purification. ES Patent 2334756 A1, 15 March 2010.

27. Flores, J.; Jimenez, V.; Belmar, J.; Mansilla, H.D.; Alderete, J.B. Inclusion Complexation of Phenol Derivatives with a $\beta$-Cyclodextrin Based Polymer. J. Incl. Phenom. Macrocycl. Chem. 2012, 53, 63-68.

28. Abay, I.; Denizli, A.; Biskin, E.; Salih, B. Removal and pre-concentration of phenolic species onto $\beta$-cyclodextrin modified poly(hydroxyethylmethacrylate-ethyleneglycoldimethacrylate) microbeads. Chemosphere 2005, 61, 1263-1272.

29. Yamasaki, H.; Makihata, Y.; Fukunaga, K. Efficient phenol removal of wastewater from phenolic resin plants using crosslinked cyclodextrin particles, J. Chem. Technol. Biotechnol. 2006, 81, 1271-1276.

30. Romo, A.; Peñas, F.J.; Isasi, J.R.; Garcia-Zubiri, I.X.; Gonzalez-Galiano, G. Extraction of phenols from aqueous solutions by $\beta$-cyclodextrin polymers. Comparison of sorptive capacities with other sorbents. React. Funct. Polym. 2008, 68, 406-413.

31. Huang, H.; Wang, J.W.; Fan, Y.F.; Tao, S.Y. Adsorption behavior of $\beta$-cyclodextrin polymer to phenol in aqueous solution. Adv. Mat. Res. 2012, 554-556, 177-180. 
32. Wang, H.; Wang, Y.; Zhou, Y.; Han, P.; Lü, X. A facile Reremoval of phenol in wastewater using crosslinked $\beta$-cyclodextrin particles with ultrasonic treatment. Clean Soil Air Water 2012, 42, 51-55.

33. Lewis, E.A.; Hansen, L.D. Thermodynamics of binding of guest molecules to $\alpha$ - and $\beta$-cyclodextrins. J. Chem. Soc. Perk. Trans. 2 1973, 15, 2081-2085.

34. Ali, W.; Hussain, M.; Ali, M.; Muushar, M.; Tabassan, M.A.R.; Mohsin, M.; Naisr, H.A.A. Evolution of Freundlich and Langmuir isotherm for potassium adsorption phenomena. Int. J. Agric. Crop Sci. 2013, 6, 1048-1054.

35. Snyder, S.A.; Villeneuve, D.L.; Snyder, E.M.; Giesy, J.P. Identification and Quantification of Estrogen Receptor Agonists in Wastewater Effluents. Environ. Sci. Technol. 2001, 35, 3620-3625.

36. Staples, C.A.; Dome, P.B.; Klecka, G.M.; Oblock, S.T.; Harris, L.R. A review of the environmental fate, effects, and exposures of bisphenol A. Chemosphere 1998, 36, 2149-2173.

37. Howdeshell, K.L.; Peterman, P.H.; Judy, B.M.; Taylor, J.A.; Orazio, C.E.; Ruhlen, R.L.; vom Saal, F.S.; Welshons, W.V. Bisphenol A is released from used polycarbonate animal cages into water at room temperature. Environ. Health Perspect. 2003, 111, 1180-1187.

38. Li, J.-H.; Zhou, B.-X.; Cai, W.-M. The solubility behavior of bisphenol A in the presence of surfactants. J. Chem. Eng. Data 2007, 52, 2511-2513.

39. Zhang, W.; Hong, C.; Pan, B.; Xu, Z.; Zhang, Q.; Lv, L. Removal enhancement of 1-naphthol and 1-naphthylamine in single and binary aqueous phase by acid-basic interactions with polymer adsorbents. J. Hazard. Mater. 2008, 158, 293-299.

40. Kitaoka, M.; Hayashi, K. Adsorption of bisphenol A by cross-linked $\beta$-cyclodextrin polymer. J. Incl. Phenom. Macrocycl. Chem. 2002, 44, 429-431.

41. Araki, M.; Kawasaki, N.; Nakamura, T.; Tanada, S. Removal of bisphenol A in soil by cyclodextrin derivatives. Toxicol. Environ. Chem. 2001, 79, 23-29.

42. Yang, Z.X.; Chen, Y.; Liu, Y. Inclusion complexes of bisphenol A with cyclomaltoheptaose ( $\beta$-cyclodextrin): solubilization and structure. Carbohydr. Res. 2008, 343, 2439-2442.

43. Zegers-Hochschild, F.; Schwarze, J.-E.; Borrero, C. Delivery routes of progesterone in assisted reproduction. Expert Rev. Obstet. Gynecol. 2006, 1, 173-182.

44. Cavalli, R.; Trotta, F.; Carlotti, M.E.; Possetti, B.; Trotta, M. Nanoparticles derived from amphiphilic $\gamma$-cyclodextrins. J. Incl. Phenom. Macrocycl. Chem. 2007, 57, 657-661.

45. Memisoglu, E.; Bochot, A.; Sen, M.; Duchene, D.; Hincal, A.A. Non-surfactant nanospheres of progesterone inclusion complexes with amphiphilic $\beta$-cyclodextrins. Int. J. Pharm. 2003, 251, $143-153$.

46. Skiba, M.; Duchene, D.; Puisieux, F.; Wouessidjewe, D. Development of a new colloidal drug carrier from chemically-modified cyclodextrins: Nanospheres and influence of physicochemical and technological factors on particle size. Int. J. Pharm. 1996, 129, 113-21.

47. Cavalli, R.; Peira, E.; Caputo, O.; Gasco, M.R. Solid lipid nanoparticles as carriers of hydrocortisone and progesterone complexes with $\beta$-cyclodextrins. Int. J. Pharm. 1999, 182, 59-69.

48. Luppi, B.; Cerchiara, T.; Bigucci, F.; Caponio, D.; Zecchi, V. Bovine serum albumin nanospheres carrying progesterone inclusion complexes. Drug Deliv. 2005, 12, 281-287.

49. Da Silveira, A.M.; Ponchel, G.; Puisieux, F.; Duchene, D. Combined poly(isobutyl cyanoacrylate) and cyclodextrins nanoparticles for enhancing the encapsulation of lipophilic drugs. Pharm. Res. 1998, 15, 1051-1055. 
50. Cerchiara, T.; Luppi, B.; Bigucci, F.; Zecchi, V. Effect of chitosan on progesterone release from hydroxypropyl- $\beta$-cyclodextrin complexes. Int. J. Pharm. 2003, 258, 209-215.

51. Nandi, I.; Bateson, M.; Bari, M.; Joshi, H.N. Synergistic effect of PEG-400 and cyclodextrin to enhance solubility of progesterone. AAPS PharmSciTech 2003, 4, 1-5.

52. Lahiani-Skiba, M.; Barbot, C.; Bounoure, F.; Joudieh, S.; Skiba, M. Solubility and Dissolution Rate of Progesterone-Cyclodextrin-Polymer Systems. Drug Dev. Ind. Pharm. 2006, 32, 1043-1058.

53. Loftsson, T.; Fridfriksdottir, H.; Sigurdardottir, A.M.; Ueda, H. The effect of water-soluble polymers on drug-cyclodextrin complexation. Int. J. Pharm. 1994, 110, 169-77.

54. Hishiya, T.; Shibata, M.; Kakazu, M.; Asanuma, H.; Komiyama, M. Molecularly imprinted cyclodextrins as selective receptors for steroids. Macromolecules 1999, 32, 2265-2269.

55. Yallapu, M.M.; Jaggi, M.; Chauhan, S.C. Curcumin Nanomedicine: A Road to Cancer Therapeutics. Curr. Pharm. Des. 2013, 19, 1994-2010.

56. Liu, J.; Chen, S.; Lu, L.; Song, L.; Guo, S.; Huang, S. Recent progress in studying curcumin and its nano-preparations for cancer therapy. Curr. Pharm. Des. 2013, 19, 1974-1993.

57. Naksuriya, O.; Okonogi, S.; Schiffelers, R.M.; Hennink, W.E. Curcumin nanoformulations: A review of pharmaceutical properties and preclinical studies and clinical data related to cancer treatment. Biomaterials 2014, 35, 3365-3383.

58. Pinho, E.; Grootveld, M.; Soares, G.; Henriques, M. Cyclodextrins as encapsulation agents for plant bioactive compounds. Carbohydr. Polym. 2014, 101, 121-135.

59. Yallapu, M.M.; Jaggi, M.; Chauhan, S.C. Poly( $\beta$-cyclodextrin)curcumin self-assembly: A novel approach to improve curcumin delivery and its therapeutic efficacy in prostate cancer cells. Macromol. Biosci. 2010, 10, 1141-1151.

60. Baglole, K.N.; Boland, P.G.; Wagner, B.D. Fluorescence enhancement of curcumin upon inclusion into parent and modified cyclodextrins. J. Photochem. Photobiol. A 2005, 173, 230-237.

61. Martin, J.D. Using XPowder: A software package for powder X-ray diffraction analysis; Spain, 2004; Available online: http://www.xpowder.com. ISBN 84-609-1497-6 (accessed on 10 October 2014).

Sample Availability: Not available.

(C) 2015 by the authors; licensee MDPI, Basel, Switzerland. This article is an open access article distributed under the terms and conditions of the Creative Commons Attribution license (http://creativecommons.org/licenses/by/4.0/). 